\title{
"Protagonismo" como Vulnerabilização em Demarcação de Terras Indígenas: o caso do acordo judicial para demarcar a terra Tapeba
}

\author{
"Protagonism" as Vulnerability in Demarcation of Indigenous Lands: \\ the case of the judicial agreement to demarcate the Tapeba land
}

Henyo Trindade Barretto Filho*1

\section{RESUmo}

Baseado em fontes documentais, mormente documentação jurídica, o artigo analisa desdobramentos recentes do procedimento de demarcação da Terra Indígena Tapeba, no município de Caucaia, zona metropolitana de Fortaleza (CE), em especial o acordo judicial celebrado entre os índios Tapeba, representantes da família Arruda, governo do estado, prefeitura municipal, Fundação Nacional do Índio (Funai) e Ministério da Justiça, visando superar um impasse judicial ao procedimento. Os Tapeba se apresentam como protagonistas desse acordo, embora se possa entender que foram forçados a aceitar um caminho para demarcar sua terra que, até agora, não surtiu efeito. Apelando à noção de vulnerabilização e à literatura crítica sobre resolução negociada de conflitos, o artigo mostra como agências do poder público investem-se da atribuição de representar o interesse geral e o ideal de democracia, ao tempo em que aspiram

\begin{abstract}
Based on documentary sources, mainly legal documentation, this article analyzes recent developments in the demarcation procedure of the Tapeba Indigenous Land, in Caucaia, Fortaleza (CE), especially the judicial agreement celebrated between the Tapeba Indians, representatives of the Arruda family, State Government, Municipality, National Foundation of the Indian (Funai) and Ministry of Justice, in order to overcome a judicial impasse that hindered the procedure. The Tapeba present themselves as protagonists of the agreement, although one can understand that they were forced to allow to a way to demarcate their land that until now proved ineffective. Appealing to the notion of vulnerability and to the critical literature on alternative dispute resolution, the article shows how public agencies assume the attribution of representing the general interest and the ideal of democracy, while simultane-
\end{abstract}

\footnotetext{
* Departamento de Antropologia, Instituto de Ciências Sociais, Universidade de Brasília (UnB). Brasília, DF, Brasil. henyo.barretto@gmail.com
} 
controlar a situação, no que podem ser definidas como formas de harmonia coercitiva e autodeterminação dirigida. Palavras-chave: demarcação de terras indígenas; Tapeba; autodeterminação dirigida. ously aiming to control the situation, in what one can understand as forms of coercive harmony and guided self-determination.

Keywords: demarcation of indigenous lands; Tapeba; guided self-determination.

Compreender a natureza constitutiva do poder implica abandonar o ideal de uma sociedade democrática como a realização de perfeitas harmonia ou transparência. $O$ caráter democrático de uma sociedade só pode ser dado na hipótese em que nenhum ator social limitado possa atribuir-se a representação da totalidade ou pretenda ter controle absoluto sobre a sua fundação.

(Mouffe, 2005, p.19)

\section{INTRODUÇÃO: OBJETO E MÉTODO}

Este artigo esboça uma breve etnografia histórica de desdobramentos do procedimento de demarcação da Terra Indígena (TI) Tapeba, do povo homônimo, no município de Caucaia, zona metropolitana de Fortaleza (CE), nos últimos 10 anos. Os Tapeba emergem das fontes tratadas como protagonistas de alguns desses desdobramentos. Não obstante, pode-se entender que eles foram sujeitos a aceitar um caminho para a efetivação da demarcação da sua terra que, até agosto de 2017, não só se mostrou ineficaz, como pode ter aberto grave precedente para casos similares em que haja conflitos de interesses entre indígenas e particulares ou entes e instância do poder público na demarcação de Terras Indígenas (TIs).

Historiamos e contextualizamos esses desdobramentos, mostrando como a demarcação da TI Tapeba tem servido de balão de ensaio para redefinições jurídico-administrativas heterodoxas no procedimento de demarcação de TIs no Brasil. O foco da análise é o Processo nº 08620.071770/2015-36 (intitulado "Acordo Tapeba - Lideranças Tapeba e os Representantes da Família Arruda"), que trata do acordo judicial entre os índios Tapeba (por meio de suas instâncias representativas), os representantes da família Arruda, o governo do estado do Ceará, a prefeitura municipal de Caucaia (PMC), a Fundação Nacional do 
Índio (Funai) e o Ministério da Justiça (MJ). Tal acordo foi firmado em 19 de fevereiro de 2016 e judicialmente homologado 2 meses depois, com o intuito expresso de superar um impasse judicial que impedia o prosseguimento da demarcação da TI. Da documentação que compõe o processo do acordo, os Tapeba emergem como protagonistas deste, malgrado evidências públicas do contrário, que exporemos aqui no intuito de problematizar o uso que se faz das noções de vulnerabilidade e autodeterminação no argumento para legitimar o acordo.

Dada a natureza e as implicações políticas da situação, optei por limitar-me a uma investigação de caráter documental, com foco no referido processo administrativo, que teve deslinde judicial, e em manifestações públicas por meio da imprensa e em sítios na web e em redes sociais - explorando a rentabilidade etnográfica dessas fontes. Poder-se-ia arguir que por se tratar de um processo contemporâneo em curso, uma etnografia histórica mais qualificada demandaria realizar, ao menos, entrevistas com atores chaves que compõem o processo, de modo a deslindar escolhas e encaminhamentos, preencher eventuais lacunas e sopesar silêncios. Não obstante, na condição de um dos atores de certo modo envolvido - e silenciado - no referido processo, a opção por explorar uma "aldeia arquivo" 3 revelou-se a mais apropriada metodológica e politicamente para o momento.

Tendo realizado uma etnografia sobre o povo Tapeba (Barretto Filho, 1993), coordenado dois grupos técnicos de identificação e delimitação da sua $\mathrm{TI}^{4}$ e acompanhado o desdobramento do procedimento de demarcação desta, ${ }^{5}$ reputo me encontrar numa posição privilegiada para analisar tais eventos recentes operando apenas com tais fontes. Não se trata de uma crítica política simples e ressentida aos Tapeba e ao acordo judicial com que se envolveram, mas sim de tomar o processo político e administrativo que leva a esse acordo como constitutivo do que seja o exercício da autodeterminação indígena nesse caso. Como sugere Vianna (2014), "levar a sério os documentos como peças etnográficas implica tomá-los como construtores da realidade tanto por aquilo que produzem na situação da qual fazem parte ... quanto por aquilo que conscientemente sedimentam" (p.47) - sendo essa a abordagem aqui. Já tendo problematizado a prática da identificação de TIs em outro momento, naquilo em que ela envolve dimensões técnicas, políticas e pragmáticas entrelaçadas (Souza Lima; Barretto Filho, 2005), este artigo constitui um registro histórico feito por alguém que está implicado no procedimento de demarcação da TI Tapeba e que, portanto, se expõe ao apresentar sua compreensão do mesmo. 
Além desta introdução, o artigo traz uma contextualização do tema, referindo-o a tendências observáveis no marco regulatório, político e institucional, e a um panorama da produção sobre o tema. As duas partes subsequentes descrevem antecedentes ao acordo judicial, mostrando como a TI Tapeba serviu de balão de ensaio para inovações heterodoxas no procedimento de demarcação de TIs, algumas das quais - como a participação de representantes de entes federados e a realização de mesas de diálogo prévias às deliberações administrativas - sinalizam para a crescente subordinação da demarcação de TIs a injunções marcadamente políticas, vulnerabilizando os direitos territoriais. Chegamos, então, ao acordo propriamente dito, procurando destacar alguns aspectos fundamentais, com ênfase na hermenêutica temerária e na noção muito particular de exercício de autodeterminação indígena que postula. Ao final, tentamos amarrar algumas considerações de ordem analítica sobre esse processo.

\section{Protagonismo E PARTICIPAÇÃo INDÍGENA NA DEMARCAÇÃO DE TIS: ENTRE AÇÕES DIRETAS E NORMAS}

Tem se avolumado o número de trabalhos que enfocam o protagonismo dos índios na conquista e na garantia dos seus territórios nos marcos da atual legislação - que reconhece aos índios os direitos originários às terras que tradicionalmente habitam - e da progressiva formalização e rotinização administrativa e técnica do procedimento de demarcação de TIs, que se verifica a partir de 1996 - data da mais recente mudança do procedimento, por meio do Decreto $n^{\circ}$ 1.775/1996 e da Portaria no 14/1996 do Ministério da Justiça, ainda em vigor. ${ }^{6}$

Essas duas normas seguem, consolidam e detalham o reconhecimento e a previsão legal de participação dos povos indígenas, no espírito da Constituição Federal de 1988. Já o Decreto no 22/1991, no $\$ 3^{\circ}$ do art. $2^{\circ}$, determinava que "o grupo indígena envolvido participará do processo em todas as suas fases". Por sua vez, o $\$ 3^{\circ}$ do art. $2^{\circ}$ do Decreto $n^{\circ} 1.775 / 96$ especificou que o grupo indígena envolvido participará do procedimento em todas as suas fases "representado segundo suas formas próprias". ${ }^{7}$ Por fim, a Portaria no 14/96, que estabelece as regras em vigor na elaboração dos Relatórios Circunstanciados de Identificação e Delimitação (RCID), determinou em seu $\$ 2^{\circ}$ que, no atendimento da segunda à quinta partes do RCID, “dever-se-á contar com a participação do grupo indígena envolvido, registrando-se a respectiva manifestação e 
as razões e fundamentos do acolhimento ou da rejeição, total ou parcial, pelo Grupo Técnico, do conteúdo de referida manifestação" (grifos nossos). As partes mencionadas do RCID (segunda à quinta) referem-se às dimensões de "habitação permanente", "atividades produtivas", "meio ambiente" e "reprodução física e cultural", que compõem a definição constitucional de "terra tradicionalmente ocupada" conforme o $\$ 2^{\circ}$ do art. 231 da Constituição Federal.

Não que antes os índios não incidissem nos procedimentos de demarcação de suas terras e que não tenha sido o reconhecimento mesmo dessa agência um dos vetores das sucessivas mudanças das normas vigentes em períodos anteriores: autocráticas, tecnocráticas e refratárias à participação indígena como não poderia deixar de ser ao tempo da ditadura civil-militar. A dissertação de Azevedo, desenvolvida em período anterior à égide da Constituição Federal de 1988, em sua análise dos processos políticos implicados na construção da TI Potiguara do povo homônimo, no litoral norte da Paraíba, talvez tenha sido uma das primeiras a dar visibilidade ao emprego do termo autodemarcação pelos povos indígenas no Nordeste naquela época (Azevedo, 1986). Não também que as normas hoje em vigor - incluindo a própria definição de "terra tradicionalmente ocupada" - não sejam em si mesmas problemáticas, se entendidas como "mecanismos político-administrativos historicamente específicos atualizados pelo Estado em busca de disciplinar a diversidade" cultural nativa contemporânea no Brasil (Barretto Filho, 2005, p.134). Portanto, formas de tentar canalizar e domesticar o protagonismo indígena nos procedimentos de demarcação de TIs. Provavelmente, a contradição mesma entre a existência de normas que preveem a participação dos indígenas em todas as fases do procedimento de demarcação, e a sua reduzida efetividade (efeito perverso da já mencionada rotinização técnica e administrativa), seja mais um fator a explicar a iniciativa de vários povos indígenas, em ações diretas de retomadas e autodemarcações.

Os trabalhos que têm enfocado o protagonismo dos povos indígenas nos processos de conquista e garantia dos seus territórios, em sua maioria, são frutos de cientistas sociais, em especial antropólogas e antropólogos, que de algum modo se viram envolvidos nesses procedimentos. Seja assessorando ativistas e associações indígenas; seja coordenando grupos técnicos de identificação de TIs específicas; seja atuando em projetos de cooperação internacional, ou como consultores contratados; tais trabalhos - tal como os RCIDs - se encaixariam naquilo que Albert (1995) chama de "etnografia didática”, ou seja, a dimensão da produção antropológica orientada pela implicação de 
profissionais em processos políticos (relatórios, laudos, assessorias, formação de opinião etc.).

De um lado, temos os artigos de Gallois e Monteiro em Kasburg e Gramkow (1999), e toda a segunda parte de Gramkow (2002), em que Gallois e Monteiro, Havt, Iglesias e Lima focalizam a agência indígena em procedimentos de autodemarcação de TIs e experiências de controle territorial na Amazônia Legal Brasileira, nos marcos do Projeto Integrado de Proteção às Terras e Populações Indígenas da Amazônia Legal (PPTAL) do Programa Piloto para a Proteção das Florestas Tropicais do Brasil (PPG7). De outro, trabalhos de viés mais acadêmico têm enfocado as ações indígenas de "retomadas" e "autodemarcações", articulando-as a mobilizações étnicas, formas de ação política e afirmação de diferença (nos marcos de uma ontopolítica), deslocando um pouco o eixo da Amazônia para o Nordeste. Brasileiro (1996) e Brasileiro e Sampaio (2012) tratam dos Kiriri; Tófoli (2010) disserta sobre os Tapeba; Alarcon (2013a; 2013b) sobre os Tupinambá; e Molina (2017) sobre os Mundurucu - realizando esta uma interessante reconstituição histórica e balanço do estado da arte dos debates em torno do tema.

Malgrado todas contribuições enfatizem a agência de sujeitos indígenas individuais e coletivos em diferentes dinâmicas socioespaciais, conjunturas, cenários e situações históricas e etnográficas, é de se notar a raridade de relatos e análises propriamente indígenas sobre esses mesmos processos. Quando existem, encontram-se em fontes de acesso intrincado: imprensa alternativa (boletins, zines, jornais de tiragem e circulação restritas), "literatura marrom" (publicações de associações da sociedade civil) e sítios da internet (sejam redes sociais, sejam homepages de associações da sociedade civil) -, havendo todo um trabalho de pesquisa e sistematização a ser feito junto a essas fontes. Este artigo as explora ainda muito timidamente. Ressalte-se que os próprios RCIDs das TIs são fontes importantes de registro e visibilização dessas vozes, que até aqui foram muito pouco exploradas nesse sentido.

Em seu objetivo de etnografar e analisar como o protagonismo indígena emerge em um processo determinado, este artigo considera e procura dialogar com esse horizonte de contribuições e preocupações. Não obstante, diante das situações etnografadas pela produção suprarreferida, tudo se passa como se o caso do acordo judicial dos Tapeba com particulares e entes públicos interessados fosse, a rigor, um contraexemplo - por razões que explicarei a seguir. 


\section{A PARTICIPAÇÃo DE REPRESENTANTES DE}

ENTES FEDERADOS NA DEMARCAÇÃO DA TI TAPEBA

Passados 25 anos de luta pela demarcação de sua terra e de incessantes vicissitudes judiciais e administrativas, em 2010 foi constituído o terceiro grupo técnico (GT) de identificação e delimitação da TI Tapeba. Visava-se, à época, sanar suposto vício procedimental apontado em entendimento judicial sui generis que anulou o procedimento anterior pela decisão na Reclamação ${ }^{\circ}$ 2.651-DF interposta pela PMC em 24 de outubro de 2007. Alegava a prefeitura que o procedimento de identificação da TI Tapeba não teria garantido a autoridade de decisão judicial anterior proferida pelo Superior Tribunal de Justiça (STJ) no Mandado de Segurança (MS) no 5.505/DF (97/0085188-5), impetrado pela PMC naquele Tribunal em 19 de novembro de 1997. A principal tese do MS de 1997 era a nulidade de todos os atos praticados pelo ministro da Justiça no procedimento de demarcação da TI Tapeba antecedentes à Portaria Declaratória n 967/97, em razão da ausência de representante do município no GT instituído para identificar a TI - tese que o STJ acolheu então, anulando a primeira identificação da TI.

O fundamento da Reclamação da PMC de 2007 foi de que a Funai teria violado a decisão judicial do STJ ao constituir o segundo GT de identificação da TI Tapeba pela Portaria no 1.185/PRES/Funai/2002, sem incluir neste a participação de um representante do município. A Reclamação foi julgada procedente pelo STJ em 11 de junho de 2008, "por ter sido descumprido o determinado no MS n 5.505”, decidindo “anular a Portaria n 97/03, que criou o grupo de trabalho para os fins indicados, bem como os atos subsequentes, por não ter sido incluído, no referido grupo, um representante do município reclamante". ${ }^{8}$ O Acórdão foi publicado em 15 de dezembro de 2008, e embargos de declaração foram interpostos pelo Ministério Público Federal (MPF) logo em seguida, mas foram rejeitados em 24 de fevereiro de 2010. Anulou-se, assim, o segundo procedimento de identificação da TI Tapeba, determinando que a eventual realização de novos estudos deveria contar com a participação do município no GT.

Ora, até 2010, quando foi publicado o Acórdão conclusivo anulando o segundo procedimento de identificação da TI Tapeba (em virtude de o GT não ter um representante da $\mathrm{PMC}$ ), não havia previsão legal de participação dos entes federados na demarcação de TIs. Foi só com a Portaria n² 2.498 do MJ, de 31 de outubro de 2011, que se regulamentou a participação dos entes federados no âmbito do procedimento administrativo de demarcação de TIs. 
Note-se que, no âmbito do marco regulatório em vigor, que já garante ao povo indígena envolvido a participação em todas as fases do procedimento de demarcação, o mesmo direito passou a ser facultado aos entes federados por meio de seus representantes. Exatamente por isso, a Portaria 2.498/2011/MJ foi objeto de forte oposição pelo movimento indígena como uma das "medidas que agravam a desconstrução dos direitos [indígenas]", materializando a "conduta omissa e conivente [do governo], de pactuação e submissão aos interesses do capital" - termos da Declaração da Mobilização Nacional em Defesa da Constituição Federal, dos Direitos Territoriais Indígenas, Quilombolas, de outras populações e da Mãe Natureza, de 3 de outubro de 2013. ${ }^{9}$ No âmbito das atividades da força-tarefa interinstitucional que trabalhou na elaboração do que veio a ser a Portaria 2.498/2011/MJ, fui convocado para depor em uma reunião da referida força-tarefa no MJ, em meados de 2011. Os representantes da Funai, do MJ e da Advocacia Geral da União (AGU) que compunham a força-tarefa pediram que eu relatasse a minha experiência de coordenador de um dos primeiros GTs a contar com a participação de representantes do município e do estado - qual seja, o GT que efetuou o terceiro estudo de identificação da TI Tapeba (ver a seguir). Assim sendo, desde antes do acordo judicial enfocado neste artigo, a demarcação da TI Tapeba tem servido como balão de ensaio para redefinições jurídico-administrativas heterodoxas relativas ao procedimento de demarcação de TIs.

\section{INCIDÊNCIAS E NEGOCIAÇÕES POLÍTICAS: A PUBLICAÇÃO DO TERCEIRO RCID DA TI TAPEBA}

Em 30 de março de 2010, pouco tempo depois da anulação judicial do segundo estudo de identificação, reuniram-se na sede da Funai, em Brasília, lideranças Tapeba, servidores da Coordenação Regional Nordeste II da Funai (CR NE II) e da sede, incluindo o presidente do órgão, representantes da Articulação dos Povos e Organizações Indígenas do Nordeste, Minas Gerais e Espírito Santo (APOINME), da PMC e do governo do estado do Ceará. Na ocasião, acordaram encaminhamentos relativos à constituição de um novo GT - o terceiro - de identificação e delimitação da TI Tapeba. Isso se deu por meio das Portarias $n^{\text {os }} 1226 /$ PRES/2010, de $1^{\circ}$ de setembro de 2010, e 1847/ PRES/2010, de 2 de novembro de 2010. Após os respectivos estudos de campo, no segundo semestre de 2010 e no primeiro semestre de 2011, o mais recente 
RCID da TI Tapeba foi finalizado em 2013, sendo aprovado em 23 de maio de 2013 por meio do Parecer Técnico no 18/CGID/2013.

$\mathrm{O} \$ 7^{\circ}$ do Art. $2^{\circ}$ do Decreto ${ }^{\circ} 1.775 / 96$ estabelece que "aprovado o relatório pelo titular do órgão federal de assistência ao índio, este fará publicar, no prazo de quinze dias contados da data que o receber, resumo do mesmo no Diário Oficial da União e no Diário Oficial da unidade federada onde se localizar a área sob demarcação" (grifos nossos). Não obstante, a publicação do terceiro RCID da TI Tapeba precisou aguardar mais 3 meses, depois de receber parecer favorável, e foi precedida de mobilizações e articulações que sugerem a subordinação de todo o procedimento a injunções marcadamente políticas.

Foi assim que, em 13 de agosto de 2013, representantes indígenas Tapeba, Pitaguary, Tabajara, Anacé, Tapuya-Kariri, Kanindé, Kalabassa e Potiguara ocuparam a sede da CR NE II em Fortaleza, como forma de pressionar o governo pela demarcação de todas as TIs no Ceará. Uma semana e meia depois, com a ocupação ainda em curso, ocorreu em Brasília, nos dias 22 e 23 de agosto, a $8^{\text {a }}$ Reunião Extraordinária da Comissão Nacional de Política Indigenista (CNPI), na qual se instalou uma "Mesa de Diálogo Permanente ... entre [o] Governo Federal e os povos indígenas", “determinada pela Presidenta” em reunião ocorrida no Palácio do Planalto em 10 de julho do mesmo ano (Brasil, 2013, p.6). Durante a ocupação à sede da CR NE II em Fortaleza e a reunião da CNPI, soube-se que o então ministro da Justiça, José Eduardo Cardozo, teria condicionado a publicação do RCID da TI Tapeba à sua apreciação pelo governo do estado do Ceará na pessoa do então governador, Cid Gomes. Tal postura foi fortemente repudiada em nota pública dos indígenas que ocupavam a sede da CR NE II, que foi lida durante a reunião da CNPI por Rosa Pitaguary:

Demonstramos, aqui, a nossa indignação pela recém postura [sic] adotada pelo Ministro da Justiça que, mesmo diante do Relatório Circunstancial [sic] de Identificação e Delimitação da Terra Indígena Tapeba já está, há alguns meses, tecnicamente concluído e, mesmo após a sua assinatura, por meio da Presidenta Interina da FUNAI ... há dois dias o Ministro, de forma tendenciosa, optou por determinar que a referida portaria só será encaminhada, para a sua publicação, no Diário Oficial da União, após o aval do Governo do Estado do Ceará. Curva-se aos caprichos do governo do Ceará, Senhor Cid Gomes. Não é um comportamento aceitável de um ministro de Estado, que merece, piamente, ser repudiado. (Brasil, 2013, p.43) ${ }^{10}$ 
Os povos e associações indígenas e as organizações indigenistas já sabiam que tal postura vinha sendo construída pelo MJ desde a "mesa de diálogo" em torno da TI Buriti do povo Terena, situada nos municípios de Sidrolândia e Dois Irmãos do Buriti, em Mato Grosso do Sul - "mesa de diálogo" esta que ocorreu no seio de uma ação judicial (Pierri, 2013). Segundo tal postura, as medidas administrativas da Funai e do MJ também deveriam ser antecedidas de tais "mesas de diálogo" com as diferentes "partes envolvidas" em procedimentos de demarcação específicos, sob a justificativa de se evitar a judicialização dos procedimentos (ibidem). É importante notar que a mesa de diálogo da TI Buriti não versava sobre limites - como é o caso do acordo Tapeba -, mas sobre a indenização da terra nua e no âmbito de uma ação judicial. Ademais, a situação do processo da TI Buriti era crítica, pois a Funai já havia perdido em todas as instâncias de mérito - não sendo esse, como veremos, o caso Tapeba.

Fato é que o Despacho no 920 da então presidente da Funai, acolhendo o resumo do RCID da TI Tapeba e aprovando as conclusões deste, foi assinado no primeiro dia útil após a referida reunião da CNPI, em 26 de agosto de 2013, por ocasião de um encontro entre aquela, o prefeito de Caucaia, o governador do Ceará e sua assessoria, e 13 lideranças indígenas Tapeba e de outros povos do Ceará. Enquanto a reunião acontecia dentro do Palácio da Abolição, cerca de duzentos indígenas Tapeba, Potiguara, Pitaguary, Anacé e Jenipapo-Kanindé, apoiadores da causa, parlamentares e membros de organizações indigenistas promoviam um ato em frente ao Palácio em favor da demarcação da TI. Após a reunião, reuniram-se na rua a presidente da Funai e as lideranças indígenas que participaram da reunião, quando comunicaram aos demais que o RCID seria publicado no Diário Oficial da União (DOU) no dia seguinte, terça-feira, 27 de agosto - como de fato o foi.

Não obstante uma conquista histórica para o povo Tapeba e mais um passo em direção à demarcação da TI, os indígenas presentes à reunião e ao ato saíram desconfiados de que o governo do estado iria contestar administrativamente o RCID. Tal suspeita se confirmou em dezembro de 2013, gerando fortes reações de lideranças Tapeba nas redes sociais, como os jovens irmãos e lideranças Cassimiro e Weibe Tapeba:

mais uma vez Cid Ferreira Gomes se demostra ... um homem sem palavra, covarde. Este, através do Governo do Estado, se diz contra a demarcação da Terra indígena Tapeba, através de uma contestação após a publicação do Relatório de Identificação e Delimitação da Terra Indígena Tapeba... ${ }^{11}$ 
notícia que não nos pegou de surpresa pela inusitada e nojenta reunião ocorrida em agosto ... pressionada pelo MJ e Casa Civil [em que] queriam que abdicássemos de uma parte da nossa terra. ${ }^{12}$

\section{Particulares Contra a TI TAPEba na Justiça: ACÓRDÃo ASSEGURA DEMARCAÇÃO?}

Paralelamente a tudo isso que ocorria na esfera administrativa, na judicial, ainda em 2013, nova ação foi interposta com o objetivo de anular o procedimento administrativo de demarcação da TI Tapeba no Tribunal Regional Federal (TRF) da 5a Região. Por meio da Medida Cautelar (MC) nº 080186592.2013.4.05.000, o Espólio de Emmanuel de Oliveira de Arruda Coelho alegava que lhe teria sido negado o direito ao contraditório no decorrer do procedimento administrativo e que seu imóvel, a Fazenda Soledade, parcialmente incidente na TI delimitada, seria explorado economicamente pela sua família desde o início do século XX. Em que pese inexistir previsão legal para notificação de particulares detentores de títulos incidentes no interior de terras em estudo pela Funai e o fato de o proponente da MC já ter apresentado contestações administrativas em diferentes etapas do procedimento demarcatório da TI, o argumento foi acatado e o procedimento foi judicialmente suspenso.

Diante desse mais novo impasse e dos "graves prejuízos causados aos Tapeba com a recorrência da suspensão do procedimento demarcatório por medidas judiciais", em vez de a Procuradoria Federal Especializada (PFE) da Funai recorrer da decisão de primeira instância, "iniciaram-se, em 2014, tratativas ... com o fito de destravar o procedimento demarcatório" da TI (Funai, 2015: fl. 100). Tais "tratativas" envolveram de diferentes modos em distintos momentos lideranças Tapeba, representantes da família Arruda, governo do estado, PMC, Funai e MJ, e culminaram na elaboração de uma minuta de Termo de Acordo entre as partes. Originou-se, assim, o processo administrativo comum, formalmente aberto em 26 de outubro de 2015, tendo como interessada a CR NE II, e que se encerrou com um único volume de 233 páginas, das quais só 140 se encontram numeradas (Funai, 2015).

O processo é aberto e tem os $40 \%$ iniciais do seu único volume ocupados pela Informação Técnica (IT) nº 07/SEGAT/CRN II-CE/2014 de 23 de outubro de 2015 e seus inúmeros anexos (Funai, 2015: fls. 2-91). A IT foi elaborada por uma competente advogada da Funai lotada, à época, na CR NE II, e que trabalhou um período na sede, em Brasília, no qual acumulou significativa 
experiência. Ela traz inúmeros documentos na reconstituição que faz do processo de negociação, efetuando uma análise favorável à proposta de minuta de Termo de Acordo entre as partes. Os limites deste artigo não me permitirão descer a detalhes, razão pela qual me aterei aos documentos e dimensões importantes para entender as noções de autodeterminação e protagonismo em jogo no processo e no acordo.

O acordo em tela previa a supressão de algumas áreas da TI Tapeba delimitada em agosto de 2013: uma parte da Fazenda Soledade de propriedade do Espólio e outras duas de interesse da PMC. As áreas de interesse do município, contudo, não são mencionadas na minuta de acordo, embora sejam referidas em um conjunto de plantas e memoriais descritivos que ocupam 36 páginas não numeradas próximas ao fim do processo. Como compensação, outras duas partes da referida fazenda permaneceriam dentro da TI delimitada, uma das quais (chamada "Gleba 3") apenas parcialmente incidente na TI, mas que seria integralmente incorporada a esta nos termos do acordo proposto. Isso ocorrendo, a família Arruda se comprometeria a desistir das ações em que se discute a nulidade do processo demarcatório da TI, e o governo do estado, a PMC e a Funai, no âmbito de suas atribuições, se empenhariam em implementar ações de política habitacional, ambiental (revitalização do rio Ceará), de saúde, saneamento, educação e etnodesenvolvimento, com ênfase nas áreas das Pontes e Jandaiguaba - as mais próximas ao limite com Fortaleza e pressionadas pela expansão urbana desordenada. Tudo isso com prazos definidos de efetivação.

\section{HERMENÊUTICA TEMERÁRIA E AUTODETERMINAÇÃo DIRIGIDA}

Ao longo desse processo de "negociação", o que os Tapeba haviam definido em setembro de 2014 como uma "proposta imoral e indecente" (Funai, 2015, fl. 4), um ano depois, em outubro de 2015, se converteu em "nossa livre manifestação ... de que as áreas ... previstas para serem excluídas da área já identificada e delimitada, não ocasionará [sic] prejuízos à nossa reprodução física e cultural, tampouco limitará o usufruto exclusivo do restante da nossa terra indígena quando totalmente regularizada" (Funai, 2015: fl. 10). Já em outubro de 2014, o presidente da Associação das Comunidades dos Índios Tapeba (ACITA), por meio do Ofício no 060/2014 à então presidente da Funai, expunha "manifestação do povo Tapeba sobre proposta mediada pelo Governo do Estado do Ceará por meio da PGE/CE", apresentando "contraproposta à proposta apresentada pela Família Arruda” (Funai, 2015: fl. 21) - indicando 
que os índios estavam se reunindo periodicamente entre si e com instituições públicas para apreciar as diferentes propostas que eram postas na mesa. Tal ofício da ACITA já trazia os lineamentos gerais do que viria a ser o conteúdo da minuta do acordo e ressaltava que o povo Tapeba, por meio da ACITA, "somente se manifestaria oficialmente a partir de uma decisão tomada de forma coletiva, tendo como repercussão nessa decisão geral, a decisão local tomada pelos integrantes da Aldeia Ponte, impactada pela Fazenda Soledade"; e que um "possível entendimento" dependeria de se garantir um conjunto de "condicionantes" (Funai, 2015: fl. 22). Tanto quanto o conteúdo substantivo das barganhas, importa a interpretação que lastreou o fracionamento da TI formalmente identificada 2 anos antes.

A referida IT 07/2014 reconheceu na minuta de Termo de Acordo "um possível conflito de normas constitucionais" que "deve se resolver sem implicar uma exclusão de uma em detrimento da outra" (Funai, 2015: fl. 15). O argumento para sustentar o acordo era que, no caso da TI Tapeba, o que estaria em jogo era "a vontade livre e soberana do povo indígena de abrir mão de parte do seu território tradicionalmente ocupado em detrimento de toda a área remanescente que foi identificada e delimitada" (destacando que a parte descartada é parcela de um imóvel titulado e que há decisão judicial favorável ao particular); e que diante da "antinomia (indisponibilidade das Terras Indígenas X exercício da autodeterminação dos povos indígenas) deve prevalecer o privilégio do reconhecimento da vontade livre e informada dos povos indígenas, sem que isso implique em diminuir a força normativa do princípio da indisponibilidade" (Funai, 2015: fl. 16, grifos nossos). A IT se esforça, assim, por caracterizar a extrema especificidade da situação.

Importa lembrar e enfatizar que, nesse caso, tratava-se apenas de decisão de primeira instância que paralisava o procedimento, mas que poderia ser revertida em instâncias superiores. Como essa ação judicial, havia e há inúmeras outras que paralisam demarcações em todo o Brasil, o que, em princípio, não autorizaria a configuração da especificidade alegada para o caso, que justificasse um acordo numa suposta integração de lacuna da lei no caso concreto. Em princípio, à luz da Constituição de 1988, nada justificaria acordos com relação às TIs, pois a cláusula da indisponibilidade está direcionada ao Estado (pois as TIs são propriedades da União), de modo que, se é que os índios poderiam dispor desse território, não seria com o aval da Funai e dos órgãos de governo que o fariam.

Chegando à sede, a minuta de Termo de Acordo foi objeto de apreciação e manifestação pelas instâncias técnicas e jurídicas competentes. Por meio da 
Informação Técnica no 09/CGID/2016 de 21 de janeiro de 2016 (Funai, 2015: fls. 99 a 104), a Coordenação Geral de Identificação e Delimitação da Diretoria de Proteção Territorial, de um lado, reiterou a preocupação com os efeitos do referido acordo para quaisquer questionamentos futuros do princípio da indisponibilidade das TIs, gerando precedente para outros casos de conflitos de interesses com particulares, ou instâncias do poder público; e de outro, lembrou que o procedimento de demarcação da TI Tapeba estava, à época, na fase de contraditório administrativo, advertindo para o risco de outras ações judiciais serem interpostas por demais particulares afetados - o que não poderia ser evitado pelo acordo, que se referia a apenas um particular. Além disso, entre outras coisas: elencou uma série de sugestões de alteração nos termos da minuta de acordo, considerados temerários por fragilizar o procedimento demarcatório como um todo; questionou a possibilidade de cumprimento dos prazos estabelecidos na minuta para a execução das medidas administrativas previstas; alertou para os problemas decorrentes de se prever, a priori, em tal acordo, a emissão da Portaria Declaratória da TI pelo ministro da Justiça, sem se ter, à época, o conhecimento pleno do teor das contestações e das análises dos aspectos técnicos e jurídicos destas; lembrou que não aparecia na minuta referência às áreas que a PMC tinha interesse em deixar fora dos limites da TI, sugerindo incluir o compromisso do governo do estado e da PMC de retirar as contestações administrativas interpostas ao procedimento. Para vários dos pontos levantados, a Informação da CGID sugeriu consultas à PFE da Funai para apreciar se os termos do acordo se adequavam a todo o marco legal que regula a demarcação de terras indígenas.

A PFE/Funai manifestou-se engenhosamente, em 12 de fevereiro de 2016, por meio da Nota n ${ }^{\circ}$ 00203/2016/COAF/PFE/PFE-FUNAI/PGF/AGU, observando que o procedimento de demarcação estava em andamento e "no prazo em que os interessados ... pode[ria]m apresentar manifestações sobre o RCID" - visto que o procedimento estava judicialmente suspenso (Funai, 2015: $2^{\text {a }}$ folha não numerada antes da fl. 140). A juízo da PFE, foi a própria Comunidade Tapeba que apresentou "fatos novos ... os quais levam a crer que as áreas mencionadas ... podem ser excluídas da área delimitada ... em razão da declaração dos indígenas de que não haveria prejuízo em sua exclusão" - "a declaração de limites levada a efeito pelo Estado não pode[ndo] se dar à revelia da vontade dos povos envolvidos" (Processo, 2015: $2^{\text {a }}$ folha não numerada antes da fl. 140, grifos nossos). Afastou a contradição entre "a necessidade de ajuste da área delimitada" e "a plena conformidade do RCID e do procedimento até então", ao argumentar "que o processo de demarcação, enquanto não finalizado, se 
reveste de um caráter dinâmico e dialógico, sendo possível que fatos ou argumentos novos modifiquem as conclusões do procedimento até sua conclusão" (Funai, 2015: $2^{\text {a }}$ folha não numerada antes da fl. 140).

Dando efetividade a esse entendimento, a versão final do acordo foi assinada 3 dias após a manifestação da PFE, em solenidade no Palácio da Abolição no dia 19 de fevereiro de 2016 com a presença do governador Camilo Santana, do então ministro da Justiça, Eduardo Cardozo, do então presidente da Funai, João Pedro Gonçalves, e de ampla delegação indígena. A notícia sobre a assinatura do acordo foi erroneamente veiculada por alguns meios como já sendo "a portaria declaratória regularizando as terras da tribo Tapeba" (Lima, 2016). Outros veículos referiram-se de modo mais adequado à "assinatura de um termo de acordo para agilizar o processo de demarcação das terras indígenas dos Tapeba ... entre a União, o Estado do Ceará, o Município de Caucaia, a Comunidade Indígena, a Funai e os proprietários da área que será entregue à tribo" -, observando que o processo estava paralisado por decisão judicial (Diniz, 2016, grifos nossos).

O acordo foi judicialmente homologado no emblemático dia 19 de abril ("Dia do Índio") de 2016, tendo a sentença sido publicada em 18 de maio. Interessante notar nos "Fundamentos" da sentença de homologação do acordo dois pontos. De um lado, o entendimento de que essa "solução, aceita tanto pelos membros da Comunidade Indígena dos Tapeba quanto pelo Espólio de Emmanuel de Oliveira Arruda, evita a eternização de um debate ... o acordo representa[ndo] o meio mais rápido de prosseguimento do processo administrativo de demarcação" (Brasil, 2016, grifos nossos). De outro, a menção de que o "feito foi concluído graças a um esforço de diversas instituições, que conseguiram chegar a uma solução consensual à demanda", destacando que "participaram da elaboração do acordo os seguintes órgãos e instituições: Estado do Ceará, Funai, União (AGU), Secretaria Estadual do Meio Ambiente (SEMA), Município de Caucaia, Espólio de Emmanuel de Oliveira Arruda Coelho e a Comunidade Indígena Tapena" (Brasil, 2016, grifos nossos).

\section{CONSIDERAÇÕES FINAIS}

Todos esses desdobramentos indicam tendências preocupantes na condução dos procedimentos de identificação de TIs em geral, pois o que se passou com a TI Tapeba está em consonância com uma postura mais ampla no tratamento de situações similares. Apesar das referências na Nota da PFE a "um processo de identificação e delimitação hígido" e à "plena conformidade do 
RCID e do procedimento", o RCID serviu apenas como plataforma para uma negociação política posterior entre partes desigualmente posicionadas para a negociação. Sintomático da desconsideração do RCID como peça técnica integral com consistência interna, é que os relatórios de vistoria in situ e de avaliações de viabilidade técnica e ambiental de obras de infraestrutura, as plantas e os mapas produzidos tanto pela Funai, quanto pelos órgãos estaduais e municipais envolvidos no processo do acordo, não dialogam nem se referem às caracterizações dessas mesmas áreas e de seus usos tradicionais pelos Tapeba, tal como apresentadas no RCID aprovado e publicado pela Funai. Relatório que, tanto assegurou a participação dos indígenas ao tempo dos estudos de campo, quanto caracterizou as formas pelas quais os Tapeba manifestaram sua concordância em relação à delimitação - tal como nele relatado. No mesmo sentido, os componentes dos dois mais recentes GTs de identificação da TI Tapeba, supostamente responsáveis pela "conformidade do RCID” e que em momentos anteriores do procedimento foram consultados para vários fins, foram ignorados como eventuais partes legítimas do "esforço de diversas instituições que conseguiram chegar a uma solução consensual" - segundo termos da já referida sentença.

Tudo se passa como se, em sua expressão de respeito à vontade livre e soberana dos Tapeba de abdicarem de parte de sua terra tradicionalmente ocupada, a hermenêutica sui generis, ambivalente e temerária que caminha no gume da navalha da constitucionalidade, com sua preocupação com o "interesse público na solução do conflito fundiário instalado na área", a "significativa e notória tensão social existente no local" e a "situação de vulnerabilidade de parte da comunidade indígena Tapeba" - segundo um dos considerandos do Termo de Acordo (Funai, 2015: c. fl. 118, grifos nossos) - precisasse resguardar tão bem o RCID a ponto de desconhecê-lo. Há que se notar uma contradição importante no argumento do processo: como poderia um povo, parte do qual se encontra em reconhecida situação de vulnerabilidade, exercer plenamente sua autodeterminação e vontade livre e informada?

No que diz respeito especificamente a essa referência à vulnerabilidade da comunidade Tapeba, esquecem as manifestações oficiais que defendem e legitimam o acordo, que ela não é uma "situação" dada: foi historicamente produzida por meio de sucessivas medidas administrativas e judiciais - portanto, do poder público como um todo - que obstaram o reconhecimento dos direitos territoriais indígenas até o presente, subordinando-os aos interesses de entes federados e particulares. Não é que parte da comunidade Tapeba é vulnerável; eles foram vulnerabilizados ao longo de mais de três décadas em que 
lutaram e conduziram retomadas parciais e localizadas de sua terra. Como observa Porto, ao criticar as lacunas das abordagens que reconhecem "a dimensão central da vulnerabilidade decorrente das iniquidades sociais agravadas por processos econômicos e políticas públicas":

A primeira [lacuna] se reflete quando o quadro teórico não explicita as origens históricas que propiciam a transformação de certo grupo social em vulnerável, ou seja, os processos de vulnerabilização de um dado território e da respetiva população. A condição de vulnerabilizadas, mais que a de vulneráveis, das populações e comunidades é importante para que possamos tanto resgatar a historicidade dos processos que dessa forma afetam grupos sociais e lugares, como também para atribuir aos grupos sociais a condição de sujeitos portadores de direitos que foram ou se encontram destituídos. (Porto, 2011, p.46, grifos nossos)

Nesse sentido, considerando todo o processo histórico de vulnerabilização a que os Tapeba foram submetidos, soa no mínimo precário o argumento de que eles exerceram sua vontade livre e soberana de abrir mão de parte do seu território tradicionalmente ocupado para assegurar o reconhecimento do restante, em condições de mínimas garantias. Sem contar que em manifestações públicas anteriores, os próprios Tapeba questionaram fortemente as posturas e medidas de autoridades públicas ao longo do procedimento de demarcação, e consideraram a proposta de acordo de "imoral e indecente". Assim, é o próprio Estado que gera a "situação de vulnerabilidade" que depois é usada como argumento para, sob a capa de "viabilizar" o direito à terra e "pacificar os conflitos", justificar a expropriação territorial. Haveria livre determinação numa situação de aparente chantagem estatal: ou eles faziam o acordo, ou continuavam sem acesso à terra (já que não havia qualquer sinalização de que a Funai e o MJ prosseguiriam com a demarcação)?

Evidencia-se, assim, no caso Tapeba, a pregnância do campo discursivo da resolução negociada de conflitos, com seu apelo ao consenso e à harmonia social (Acselrad; Bezerra, 2007; Nuñez Viégas, 2016). Trata-se de tendência cada vez mais comum no Poder Judiciário de recorrer a procedimentos de conciliação, ou resolução negociada de conflitos, envolvendo partes assimétricas, lógica que esvazia o Judiciário como instância de garantia de direitos para os que destes mais necessitam. O ente "vulnerável" fica à mercê de sua própria sorte na negociação, sem poder contar sequer com um juízo garantidor, e o Judiciário encontra-se na situação de validar acordos potencialmente 
violadores da Constituição, somente para atender a expectativa de pacificação social por meio de acordos.

Parafraseando Mouffe a partir de Nuñez Viégas, o consenso pode ser considerado como "um arranjo histórico e contingente, fruto de um tipo de formulação política que busca hegemonizar seus conteúdos socialmente" (Nuñez Viégas, 2016, p.31-32):

O consenso, em sua proposta de abranger a todos os interesses, é o resultado de uma imposição política excludente, pois desconsidera outras formas de tomadas de decisão, outras maneiras de conceber o jogo democrático, uma vez que as relega à condição de formulações políticas inferiores. (Nuñez Viégas, 2016, p.32)

Assim sendo, “o processo de exclusão obtido por meio do consenso é justificado pela argumentação de que tais exclusões são produto do livre exercício da razão prática' e do acordo livre resultante de seus procedimentos racionais" (Nuñez Viégas, 2016, p.32). Trata-se, assim, de uma "harmonia coercitiva" que "funciona para silenciar pessoas que falam ou atuam colericamente" - termos de Laura Nader reavidos por Nuñez Viégas (2016, p.36):

Cria-se, com a busca pela constituição da resolução negociada, a expectativa de que a desjudicialização dos conflitos mediante o uso de métodos consensuais contribua para a obtenção de uma nova forma de "pacificação da sociedade" - ao identificar [a] resolução negociada como formas de obtenção de soluções consensuais que se dão em contraposição ao uso do direito como "forma regulamentada de fazer a guerra" (Foucault, 2011, p.56-57), ou seja, como forma de se evitar "o comando frio e enérgico de uma sentença" (De Mio, 2005, p.28). (Nuñez Viégas, 2016, p.35)

Receia-se que a partir da argumentação engenhosa da Funai, abra-se um precedente a se aplicar em outros casos de demarcações paralisadas. Em vez de Funai e MJ investirem na defesa qualificada dos procedimentos, é possível que tal solução seja apontada para desafogar o Judiciário, fazer andar os procedimentos e "pacificar" os conflitos à custa dos territórios.

Ainda que admitida a plausibilidade do acordo, com toda a sua argumentação relativa ao protagonismo dos Tapeba no processo, até o momento (agosto de 2017), sua efetividade ainda resta por ser demonstrada. Após a homologação do acordo, a família Arruda desistiu da ação e a Funai prosseguiu com a análise técnica e jurídica das 39 contestações administrativas ao procedimento demarcatório, já que três foram retiradas: a da PMC, a do governo do 
Ceará e a do Espólio Emmanuel Arruda. Os prazos, contudo, não foram cumpridos, pois embora a Funai tenha dado conta das contestações, o MJ não decidiu no prazo de 30 dias a partir da data da extinção da ação ordinária sobre a "tradicionalidade da ocupação Tapeba" - tal como (re)definida por meio do acordo. Todos os demais prazos decorrentes desse estouraram. Como se não bastasse, a crise política instaurada com a mudança no comando do Poder Executivo não assegura que o $\mathrm{MJ}$ cumprirá o acordado. Uma das últimas medidas oficiais registradas em relação ao acordo foi a expedição da Portaria ${ }^{\circ} 894$ da Funai, de 28 de novembro de 2016, que, dando provimento à Cláusula 12a do Termo de Acordo, instituiu um Comitê Gestor específico para acompanhar este, com previsão de funcionamento enquanto perdurarem as obrigações previstas. Composto por 13 membros, sendo cinco Tapeba pela ACITA, e coordenado pela advogada que deflagrou o processo administrativo que resultou no Acordo, não há notícias sobre o funcionamento do Comitê.

Por fim, sob a alegação do custo de transação de manter um processo judicial nas instâncias superiores por prazo indeterminado e do risco à vida, à integridade física e à dignidade humana dos indígenas (resultante de um processo histórico de vulnerabilização em que o Estado é coator), o caso Tapeba escancara a orientação de subordinar as medidas administrativas da Funai e do MJ a acordos políticos explícitos: sejam estes prévios, para legitimar tais medidas (condicionando a aprovação do RICD), com forte oposição dos índios; sejam posteriores, para emendá-las (re/descaracterizando a tradicionalidade), com o suposto apoio livre e soberano deles. Instala-se, assim, uma lógica de câmara de arbitragem e conciliação de conflitos com entes particulares e distintas instâncias do poder público ao longo do procedimento de demarcação da TI (sem que haja previsão legal para tanto), na qual os índios se encontram em posição estruturalmente subordinada. Um conjunto de agências de distintos níveis do Poder Executivo investe-se da atribuição de representar o interesse público e o ideal de democracia como realização da harmonia perfeita; quando podemos entender, ao fim e ao cabo, que aspiram controlar a situação, no que pode ser interpretado como mais uma instância da "'autodeterminação indígena' dirigida” de que nos fala Baines (1993).

\section{REFERÊNCIAS}

ACSELRAD, Henri; BEZERRA, Gustavo das Neves. Inserção Econômica Internacional e 'Resolução Negociada' de Conflitos Ambientais na América Latina. Quito, Equador, 2007. Disponível em: http://www.observaconflitos.ippur.ufrj.br/novo/ 
analises/HenriAcselrad-Resoluçãonegociadadeconflitos.pdf; Acesso em: 6 ago. 2017.

ALARCON, Daniela Fernandes. A forma retomada: contribuições para o estudo das retomadas de terras, a partir do caso Tupinambá da Serra do Padeiro. Ruris Revista do Centro de Estudos Rurais, Campinas: Unicamp, v.7, n.1, p.99-126, mar. 2013a.

. O retorno da terra: as retomadas na aldeia Tupinambá da Serra do Padeiro, sul da Bahia. Dissertação (Mestrado em Ciências Sociais) - CEPPAC, Universidade de Brasília (UnB). Brasília, 2013b.

ALBERT, Bruce. Anthropologie appliquée ou 'anthropologie impliquée'? Ethnographie, minorités et développement. In: BARÉ, Jean-François (Org.) Les Applications de l'Anthropologie: un essai de refléxion collective depuis la France. Paris: Karthala, 1995. p.87-118.

AZEVEDO, Ana Lucia L. A terra somo nossa: uma análise de processos políticos na construção da terra Potiguara. Dissertação (Mestrado em Antropologia Social) PPGAS/Museu Nacional, Universidade Federal do Rio de Janeiro (UFRJ). Rio de Janeiro, 1986.

BAINES, Stephen G. A política indigenista governamental e os Waimiri-Atroari: administrações indigenistas, mineração de estanho e a construção da "autodeterminação indígena” dirigida. Revista de Antropologia, São Paulo: USP, v.36, p.207-237, 1993.

BARRETTO FILHO, Henyo T. Disciplinando a Diversidade Cultural: uma perspectiva antropológica sobre a Portaria 14. In: SOUZA LIMA, Antonio Carlos; BARRETTO FILHO, Henyo T. (Org.) Antropologia e identificação: os antropólogos e a definição de terras indígenas no Brasil, 1977-2002. Rio de Janeiro: Contra Capa; Laced; CNPq; Faperj; IIEB, 2005. p.119-135.

Tapebas, Tapebanos e Pernas-de-Pau: etnogênese como processo social e luta simbólica. Dissertação (Mestrado em Antropologia Social) - PPGAS/Museu Nacional, Universidade Federal do Rio de Janeiro (UFRJ). Rio de Janeiro, 1993.

. Terras Indígenas na Amazônia hoje: fraturas na narrativa hegemônica. In: SAUER, Sérgio; ALMEIDA, Wellington (Org.) Terras e territórios na Amazônia: demandas, desafios e perspectivas. Brasília: Ed. UnB, 2011. p.221-236.

BARRETO FILHO, Henyo T.; CORREIA, Cloude de S. Gestão Ambiental e/ou Territorial de/em Terras Indígenas: subsídios para a construção da Política Nacional de Gestão Ambiental em Terras Indígenas conforme Portaria Interministerial ${ }^{\circ}$ 276/2008. Brasília: GIZ; MMA; Funai, 2009.

BRASIL. $3^{\text {a }}$ Vara Federal do Ceará (Fortaleza). Procedimento Ordinário. Processo $n^{\circ}$ 0800056-17.2013.4.05. 8100. Sentença - Homologação de Acordo - Comunidade Indígena Tapeba. Autor: Danielle Miranda de Oliveira Arruda Gomes. Réu: Funai. 
Relator: George Marmelstein Lima - Juiz Federal Substituto. Fortaleza, 18 maio 2016.

BRASIL. Ata da $8^{\text {a }}$ Reunião Extraordinária da CNPI. Salão Negro do Ministério da Justiça, Brasília, DF, 22 e 23 de agosto de 2013. Disponível em: http://www.funai. gov.br/arquivos/arquivos_old/conteudo/presidencia/pdf/Atas_CNPI/Ata_8_ Reuniao_Extraordinaria.pdf; Acesso em: 6 ago. 2017.

BRASILEIRO, Sheila. A organização política e o processo faccional no povo indígena Kiriri. Dissertação (Mestrado em Sociologia) - FFCH, Universidade Federal da Bahia (UFBA). Salvador, 1996.

BRASILEIRO, Sheila; SAMPAIO, José Augusto L. Estratégias de negociação e recomposição territorial Kiriri. In: CARVALHO, Maria Rosário de; CARVALHO, Ana Magda (Org.) Índios e caboclos: a história recontada. Salvador: Ed. UFBA, 2012. p.147-166.

CARRARA, Sérgio. Crime e loucura: o aparecimento do manicômio judiciário na passagem do século. Rio de Janeiro: Eduerj; São Paulo: Edusp, 1998.

DINIZ, Kézya. Camilo e Cardozo assinam acordo histórico para demarcação de terras dos Tapeba. Blog Política com K, em 19 fev. 2016. Disponível em: http://www.politicacomk.com.br/camilo-e-cardozo-assinam-acordo-historico-para-demarcacao-de-terras-dos-tapeba/; Acesso em: 6 ago. 2017.

FUNAI. PROCESSO nº 08620.071770/2015-36. Acordo Tapeba - Lideranças Tapeba e os Representantes da Família Arruda. Administrativo comum. Interessada: Coordenação Regional Nordeste II (Requerente - Polo Ativo). Abertura, 26 out. 2015.

GRAMKOW, Marcia Maria (Org.) Demarcando terras indígenas II: experiências e desafios de um projeto de parceria. Brasília: Funai; PPTAL; GTZ, 2002.

KASBURG, Carola; GRAMKOW, Marcia Maria (Org.) Demarcando terras indígenas: experiências e desafios de um projeto de parceria. Brasília: Funai; PPTAL; GTZ, 1999.

LIMA, Eliomar. Ministro da Justiça vem assinar portaria regularizando terras da tribo Tapeba (da Coluna 'Vertical' do jornal O Povo). Blog do Eliomar, 18 fev. 2016. Disponível em: http://blog.opovo.com.br/blogdoeliomar/ministro-da-justica-vem-assinar-portaria-regularizando-terras-da-tribo-tapeba/; Acesso em: 6 ago. 2017.

LIMA, Ronaldo de Q. A Saga do Povo Tapeba na luta pela demarcação da terra. EcoDebate: site de informações, artigos e notícias socioambientais. Notícia em 28 ago. 2013. Disponível em: https://www.ecodebate.com.br/2013/08/28/a-saga-do-povo-tapeba-na-luta-pela-demarcacao-da-terra/; Acesso em: 6 ago. 2017.

MOLINA, Luísa Pontes. Terra, luta, vida: autodemarcações indígenas e afirmação da diferença. Dissertação (Mestrado em Antropologia Social) - PPGAS, Universidade de Brasília (UnB). Brasília, 2017. 
MOUFFE, Chantal. Por um modelo agonístico de democracia. Revista de Sociologia e Política, Curitiba: UFPR, n.25 (Dossiê 'Democracias e Autoritarismos'), p.11-23, nov. 2005.

NUÑEZ VIÉGAS, Rodrigo. O campo da resolução negociada de conflito: o apelo ao consenso e o risco do esvaziamento do debate político. Revista Brasileira de Ciência Política, Brasília, n.21, p.7-44, set./dez. 2016.

OLIVEIRA, João Pacheco de. Ensaios em Antropologia Histórica. Rio de Janeiro: Ed. UFRJ, 1999.

. Etnografia enquanto compartilhamento e comunicação: desafios atuais às representações coloniais da antropologia. In: FELDMAN-BIANCO, Bela (Org.) Desafios da Antropologia Brasileira. Brasília: ABA, 2013. p.47-74.

. O Nascimento do Brasil e outros ensaios: "pacificação", regime tutelar e formação de alteridades. Rio de Janeiro: Contra Capa, 2016.

. (Org.) Indigenismo e territorialização: poderes, rotinas e saberes coloniais no Brasil contemporâneo. Rio de Janeiro: Contra Capa, 1998.

OLIVEIRA, Kelly E. Diga ao povo que avance! Movimento Indígena no Nordeste. Recife: Massangana/Fundação Joaquim Nabuco, 2013.

PIERRI, Daniel C. Diálogo ou negociação? Divergência entre Governo e movimento indígena marca a $8^{\mathrm{a}}$ Reunião Extraordinária da CNPI. Portal do Centro de Trabalho Indigenista, em 17 out. 2013. Disponível em: http://trabalhoindigenista.org.br/ dialogo-ou-negociacao-divergencia-entre-governo-e-movimento-indigena-marca-8a-reuniao-extrao-2/; Acesso em: 6 ago. 2017.

PORTO, Marcelo Firpo de S. Complexidade, processos de vulnerabilização e justiça ambiental: um ensaio de epistemologia política. Revista Crítica de Ciências Sociais, Coimbra, Portugal: Centro de Estudos Sociais, n.93, p.31-58, jun. 2011.

SOUZA LIMA, Antonio Carlos; BARRETTO FILHO, Henyo T. (Org.) Antropologia e identificação: os antropólogos e a definição de terras indígenas no Brasil, 19772002. Rio de Janeiro: Contra Capa; Laced; CNPq; Faperj; IIEB, 2005.

TÓFOLI, Ana Lúcia F. de. As retomadas de terras na dinâmica territorial do povo indígena Tapeba: mobilização étnica e apropriação espacial. Dissertação (Mestrado em Sociologia) - PPGS, Universidade Federal do Ceará (UFC). Fortaleza, 2010.

TURNER, Victor. Dramas, campos e metáforas. Niterói: Ed. UFF, 2008.

VIANNA, Adriana. Etnografando documentos: uma antropóloga em meio a processos judiciais. In: CASTILHO, Sergio Ricardo R.; SOUZA LIMA, Antonio Carlos; TEIXEIRA, Carla Costa (Org.) Antropologia das Práticas de Poder: reflexões etnográficas entre burocratas, elites e corporações. Rio de Janeiro: Contra Capa, 2014. p.43-70. 


\section{NOTAS}

${ }^{1}$ Doutor em Ciência Social (Antropologia Social) pela Faculdade de Filosofia Letras e Ciências Humanas (FFLCH) da Universidade de São Paulo (USP), 2001.

${ }^{2}$ Este artigo traduz única e exclusivamente a minha compreensão do caso aqui descrito e analisado, não correspondendo às posições de nenhuma das instituições às quais estive e estou vinculado, ou para as quais prestei serviço como colaborador na identificação da Terra Indígena Tapeba, e muito menos à concepção dos próprios Tapeba, que têm as suas formas de expressão e organização, e instituições representativas. Agradeço muito a Nina Paiva Almeida, colega antropóloga, Indigenista Especializada e ex-Coordenadora de Delimitação e Análise da Coordenação-Geral de Identificação e Delimitação da Diretoria de Proteção Territorial da Fundação Nacional do Índio (Funai), e a Carolina Augusta de Mendonça Rodrigues dos Santos, membro da Procuradoria Federal Especializada da Funai, tanto por terem me possibilitado acesso ao processo aqui analisado (a primeira), quanto por leituras atentas e críticas de primeiras formulações deste texto (ambas). Esta versão do texto também se beneficiou dos comentários de colegas antropólogas presentes à apresentação que fiz deste na Reunião do Lageri (Laboratório e Grupo de Estudos em Relações Interétnicas) da Universidade de Brasília (UnB), em 23 de junho de 2017, em especial Giovana Tempesta, Marianna Holanda, Marcela Coelho de Souza e Nina Almeida. Agradeço ao professor Stephen Grant Baines, meu colega no Departamento de Antropologia da UnB, pelo convite e a oportunidade de expor o trabalho. Toda e qualquer imprecisão ou inconsistência que tenha persistido, contudo, é de minha inteira responsabilidade.

${ }^{3}$ Termo usado por Sérgio Carrara para se referir ao "universo etnográfico feito de documentos acumulados ... sobre o qual nos debruçamos" (CARRARA, 1998 apud VIANNA, 2014, p.46).

${ }^{4}$ Fui coordenador dos Grupos Técnicos de identificação e delimitação da TI Tapeba constituídos pelas Portarias no 1.185/PRES/FUNAI de 11 nov. 2002, 097/PRES/FUNAI de 12 fev. 2003, 1226/PRES/2010 de 1 set. 2010 e 1847/PRES/2010 de 2 nov. 2010, que resultaram em dois estudos de identificação distintos, realizados em dois períodos diferentes e publicados, respectivamente, em 2006 e 2015.

${ }^{5}$ Numa espécie de monitoramento remoto dos efeitos da nossa produção técnica, que é um dos desdobramentos possíveis da "etnografia como compartilhamento", que marca a antropologia contemporânea junto a povos indígenas no Brasil (OLIVEIRA, 2013).

${ }^{6}$ Sobre os impactos acumulados da formalização e da rotinização administrativa do procedimento de demarcação de TIs na ampliação do reconhecimento dos direitos territoriais indígenas, ver BARRETO FILHO, 2011; BARRETO FILHO; CORREIA, 2009; SOUZA LIMA; BARRETO FILHO, 2005.

${ }^{7}$ Note-se a mudança do termo "processo" para "procedimento" de demarcação entre o Decreto no 22/1991 e o Decreto no 1.775/1996. Foge aos limites deste artigo proceder a uma hermenêutica jurídica detalhada dessa mudança. Cumpre, contudo, observar que isso deve ter ocorrido em função da consolidação do entendimento segundo o qual a demarca- 
ção de TIs é um procedimento administrativo assente em um direito territorial originário que a Constituição Federal reconhece. Assim sendo, embora se possa falar na demarcação de uma dada TI como um "processo social", no sentido amplo do termo (quiçá até, um "drama social" - TURNER, 2008), como faço algumas vezes ao longo do artigo, dou preferência ao termo "procedimento" exatamente para enfatizar o entendimento mencionado - e porque, como veremos adiante, é uma dada manipulação da linguagem do Direito que nos interessa aqui.

${ }^{8}$ Observe-se que o STJ anulou a portaria que constituiu o GT de levantamento fundiário (n 097/2003) e "os atos subsequentes", e não a que instituiu o GT dos estudos técnicos de identificação e delimitação ( $\mathrm{n}^{\circ}$ 1.185/2002).

${ }^{9}$ Disponível em: https://pib.socioambiental.org/en/noticias?id=131959; Acesso em: 6 ago. 2017.

${ }^{10}$ Malgrado a Ata (BRASIL, 2013) ser fonte necessária e suficiente para a situação aqui descrita, importa notar que esta repercutiu em portais de notícias (LIMA, 2013) e de organizações indigenistas da sociedade civil (PIERRI, 2013) - matéria esta também reproduzia no site da Mobilização Nacional Indígena.

${ }^{11}$ Disponível em: https://www.facebook.com/joao.tapeba/posts/564654703612930; Acesso em: 6 ago. 2017.

${ }^{12}$ Disponível em: https://www.facebook.com/weibe.tapeba/posts/3735458602985; Acesso em: 6 ago. 2017.

Artigo recebido em 2 de maio de 2017. Aprovado em 14 de julho de 2017. 